\title{
Seminal vesicle metastasis after partial hepatectomy for hepatocellular carcinoma
}

\author{
$\mathrm{Li} \mathrm{Gong}^{1+}$, Minwen Zheng ${ }^{2+}$, Yanhong $\mathrm{Li}^{1}$, Wendong Zhang ${ }^{1}$, Wangjun $\mathrm{Bu}^{3}$, Lifang Shi ${ }^{4}$, Wei Zhang ${ }^{1 *}$ and \\ Hong Yan $^{5^{*}}$
}

\begin{abstract}
Background: Metastasis to the seminal vesicle is extremely rare for hepatocellular carcinoma (HCC). To our knowledge, it has been not reported in literature. The purpose of the present paper was to report a case of metastasis to the seminal vesicle after HCC resection, along with its histological features and immunohistochemical characteristics.

Case Presentation: A 46-year-old Chinese man was admitted to our hospital due to abdominal distension. He had a history of HCC related to hepatitis B virus infection. Moreover, left partial hepatectomy was performed in another hospital 28 months ago, and right partial hepatectomy for HCC recurrence in our hospital 4 months ago. After resection, radiofrequency ablation therapy had been performed. About 27 months after the initial operation, contrastenhanced computed tomography (CT) of the pelvic cavity revealed a mass with homogeneous enhancement in the seminal vesicle. Transrectal needle biopsy revealed a poorly differentiated adenocarcinoma. Therefore, seminal vesiculectomy was resected. The histological diagnosis of the removed tumor was compatible with the original HCC. Immunohistochemical examination demonstrated that the tumor cells were positive for glypican-3 (GPC3), alphafetoprotein (AFP), hepatocyte paraffin-1 (Hep Par 1), cytokeratin 18 (CK 18), and hepatocyte antigen, which confirmed that the seminal vesicle tumor was a metastatic tumor of HCC. However, CT subsequently revealed multiple metastatic foci in the abdominal and pelvic cavities in May 2009 and August 2009, respectively.

Conclusion: The seminal vesicle is an extremely rare metastatic site for HCC, and the prognosis is very poor. A combination of clinical and pathological features is necessary for a correct diagnosis, and primary tumor should be excluded before diagnosing metastatic foci.
\end{abstract}

Keywords: seminal vesicle hepatocellular carcinoma, metastasis, clinical pathology

\section{Background}

Hepatocellular carcinoma (HCC) is one of the most common malignancies worldwide, accounting for nearly one million new cases each year [1]. The long-term prognosis for HCC remains poor, with a 5 -year survival rate of $<5 \%$ [2], and intrahepatic and extrahepatic metastasis are the most important factors. The liver is the most common site of HCC metastasis, accounting

\footnotetext{
* Correspondence: zhwlyh@fmmu.edu.cn; yhongb@fmmu.edu.cn

+ Contributed equally

${ }^{1}$ The Helmholtz Sino-German Laboratory for Cancer Research, Department of Pathology, Tangdu Hospital, the Fourth Military Medical University, 710038

Xi'an, Shaanxi Province, PR China

${ }^{5}$ Depatment of Ophthalmology, Tangdu Hospital, the Fourth Military Medical University, 710038 Xi'an, Shaanxi Province, PR China

Full list of author information is available at the end of the article
}

for approximately $85 \%$ to $90 \%$ of all cases [3]. Extrahepatic metastases have been reported to occur in 13.5\% to $42 \%$ of HCC patients [4-6]. The most frequent sites of extrahepatic metastases are lung, abdominal lymph node, and bone $[4,7,8]$. To our knowledge, it has not been reported in literature that HCC metastasize to the seminal vesicle. Here we report the case of a 46-year-old man with metastatic HCC to the seminal vesicle after a liver resection for $\mathrm{HCC}$ and recurrence, and observed its histological and immunohistochemical characteristics.

\section{Case presentation}

A 46-year-old Chinese man was admitted to our hospital due to abdominal distension in January 2009. It was the second time that he was as an inpatient of our

\section{Biomed Central}


hospital. The patient had a history of hepatitis B for approximately ten years. Moreover, his mother, two older brothers, and older sister had histories of hepatitis B. Among them, one older brother died from HCC three years ago. He began to notice his weight loss since June 2006, and performed a health examination in local hospital in August 2006. Laboratory test results included

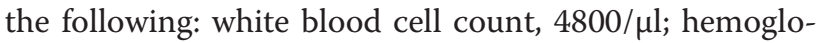
bin, $10.3 \mathrm{~g} / \mathrm{dl}$; platelets, $84 \times 10^{3} / \mu \mathrm{l}$; aspartate aminotransferase, $42 \mathrm{U} / \mathrm{L}$; alanine aminotransferase, $30 \mathrm{U} / \mathrm{L}$ (Table 1). Hepatitis B surface antigen, hepatitis B e antigen, and hepatitis $B$ core antibody were positive. The level of serum alpha-fetoprotein (AFP) was elevated to $3350 \mathrm{ng} / \mathrm{ml}$ (normal level $<20 \mathrm{ng} / \mathrm{ml}$ ), whereas serum carcinoembryonic antigen (CEA) and human chorionic gonadotropin (HCG) levels were within normal limits. Abdominal ultrasound examination revealed a solitary mass, which was determined to be HCC by liver needle biopsy. Sequentially, the patient underwent partial resection of the left anterior segment of the liver (about $2 \mathrm{~cm}$ in diameter) in local hospital in September 2006. After leaving the hospital, the patient received thymic peptide injections twice a week, but the dosage was not provided. About half a year after the initial operation, abdominal ultrasound examination revealed a mass in the right lobe of the liver, which was determined to be recurrent HCC (Figure 1). Thus, regular (one time/three months) radiofrequency ablation therapy $(60 \mathrm{~W}, 2 \mathrm{~min} /$ time; the total 3 times) and transarterial interventions (embolization or chemoembolization) were performed until September 2008. During therapy, the serum level of AFP was elevated (21.51-4689 $\mathrm{ng} / \mathrm{ml}$ ) (the details could be seen in table 1). However, abdominal ultrasound examination also revealed multiple solid occupation in the liver (Figure 2 and 3). Thus, the patient underwent partial resection of the right anterior segment for HCC recurrence in our hospital on September 20, 2008. After operation, the patient was not received any antitumoral therapy due to his weakness. On December 23, 2008, he went to see a doctor for abdominal distension in local hospital. Contrast-enhanced computed tomography $(\mathrm{CT})$ of the pelvic cavity revealed a mass $(5.0 \mathrm{~cm}$ in diameter $)$ with homogeneous enhancement in the seminal vesicle. Transrectal needle

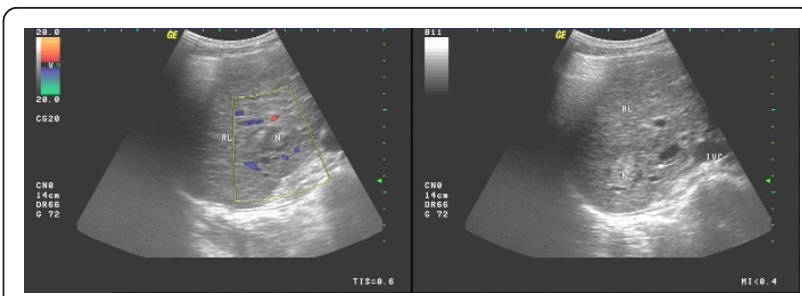

Figure 1 US image shows that the echogenic dots thicken slightly, and the echo strengthen slightly. A well-defined and regular-appearance echo zone $(2.7 \mathrm{~cm} \times 2.3 \mathrm{~cm})$ is found in the right lobe of the liver. Moreover, A well-defined, and heterogeneous hyperechoic mass $(2.1 \mathrm{~cm} \times 2.0 \mathrm{~cm})$ is found in the right lobe neighboring to the porta hepatis.

biopsy revealed a poorly differentiated adenocarcinoma with histological characteristic similar to that of the original HCC. Considering the patient's history, the doctors diagnosed the mass in the seminal vesicle as a metastatic focus. Unfortunately, the CT image and biopsy were not obtained from the other hospital. In order to receive further treatment, he came to our hospital. During the operation, only a mass with the size of $4.8 \mathrm{~cm}$ in diameter was found in left seminal vesicle, but involved right seminal vesicle. Thus, bilateral seminal vesicle and prostate were resected. Macroscopically, the structure of the seminal vesicle was unclear and replaced by tumor tissues with hemorrhage. Histologically, the removed tumor was found to be compatible with the original HCC. Tumor cells arranged in trabecular, solid, or tubular patterns. Nuclei and nucleoli were prominent, and the cytoplasm was scanty and basophilic (Figure 4). Moreover, immunohistochemical examination demonstrated that the tumor cells were positive for glypican-3 (GPC3) (Figure 5), AFP (Figure 6), hepatocyte paraffin-1 (Hep Par 1), cytokeratin (CK)18, and hepatocyte antigen, but negative for CK7, CK20, placental alkaline phosphatase (PLAP), prostate-specific antigen (PSA), cancer antigen 125 (CA125), epithelial membrane antigen (EMA), cluster of differentiation (CD) 117, and CEA, which confirmed that the seminal vesicle tumor was metastatic HCC. In May 2009, a abdominal CT reviewing revealed multiple metastatic foci in the abdominal cavity in local hospital. Thus, the patient came to our hospital again in order to receive further therapy by the

Table 1 Laboratory test results of blood routine examination, liver function and serous AFP at different time

\begin{tabular}{|c|c|c|c|c|c|c|c|}
\hline Date & $\mathrm{WBC}\left(10^{9} / \mathrm{I}\right)$ & $\mathrm{RBC}\left(10^{12} / \mathrm{l}\right)$ & $\mathrm{HGB}(\mathrm{g} / \mathrm{l})$ & $\operatorname{PLT}\left(10^{9} / \mathrm{I}\right)$ & $\operatorname{ALT}(\mathrm{u} / \mathrm{l})$ & $\mathrm{AST}(\mathrm{u} / \mathrm{l})$ & $\operatorname{AFP}(\mathrm{ng} / \mathrm{ml})$ \\
\hline 06.09 & 4.80 & 3.85 & 103 & 84 & 30 & 42 & 3350 \\
\hline 07.03 & 3.62 & 4.32 & 121 & 88 & 28 & 40 & 2249 \\
\hline 07.09 & 5.03 & 4.55 & 139 & 82 & 32 & 38 & 897 \\
\hline 08.09 & 4.71 & 4.40 & 135 & 135 & 135 & 78 & 772 \\
\hline 09.01 & 4.43 & 3.44 & 103 & 125 & 14 & 20 & 3350 \\
\hline 09.08 & 4.89 & 4.49 & 133 & 174 & 19 & 25 & 4689 \\
\hline
\end{tabular}




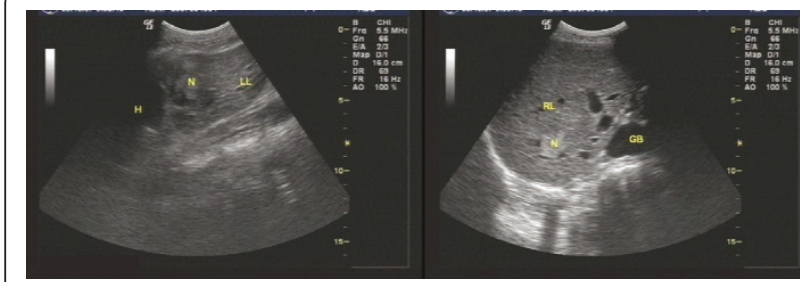

Figure 2 US image shows that the echogenic dots are intensive, dim, and mal-distributed. An ill-defined and irregular dense echo zone $(3.7 \mathrm{~cm} \times 3.3 \mathrm{~cm})$ is found in left lobe, and the echogenic dots are confused and disorderly. Moreover, a dense echo zone $(1.8 \mathrm{~cm} \times 1.7 \mathrm{~cm})$ is found in right posterior lobe, and the internal echo are well-distributed.

iatrotechnique of microwave. Two solid and bad mobility masses, with the size of $6 \mathrm{~cm}$, were touched in the lower abdomen by physical examination. Laboratory test results included the following: white blood cell count, $4890 / \mu \mathrm{l}$; red blood cell count, $4490 \times 10^{3} / \mu \mathrm{l}$; hemoglobin, $13.3 \mathrm{~g} / \mathrm{dl}$; platelets, $174 \times 10^{3} / \mu \mathrm{l}$; aspartate aminotransferase, $25 \mathrm{U} / \mathrm{L}$; alanine aminotransferase, $19 \mathrm{U} / \mathrm{L}$. The level of serum AFP was elevated to $4689 \mathrm{ng} / \mathrm{ml}$ (Table 1). Abdominal ultrasound examination revealed that there was a dense echo zone in right anterior lobe and right posterior lobe of the liver, respectively. Moreover, a low echo area with clear circumscription was found at the ahead of head of pancreas. Thus, all these foci were treated by microwaves. However, CT imaging revealed multiple metastatic foci in the abdominal and pelvic cavities in September 2009 (Figure 7). Of course, the Written informed consent was obtained from the patient for publication of this case report and any accompanying images.

\section{Discussion}

Metastasis from the liver to extrahepatic tissues is not common for HCC (13.5\%-42\% of cases) and has a poor prognosis [4-6]. For unknown reasons, the seminal vesicle is an extremely rare site of metastasis for $\mathrm{HCC}$; therefore, clinical data is limited.

Tumors of the seminal vesicles may be primary tumors or secondary tumors originating from adjacent

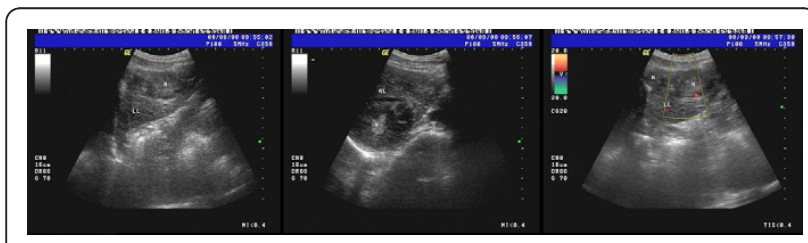

Figure 3 US image shows that the echogenic dots are intensive, dim, and heterogeneous. Multiple dense echo zones with inequality of size are found, and the larger $(5.0 \mathrm{~cm} \times 3.1 \mathrm{~cm}$ ) locats in the left lobe, and the internal echo is well-distributed insufficiently.

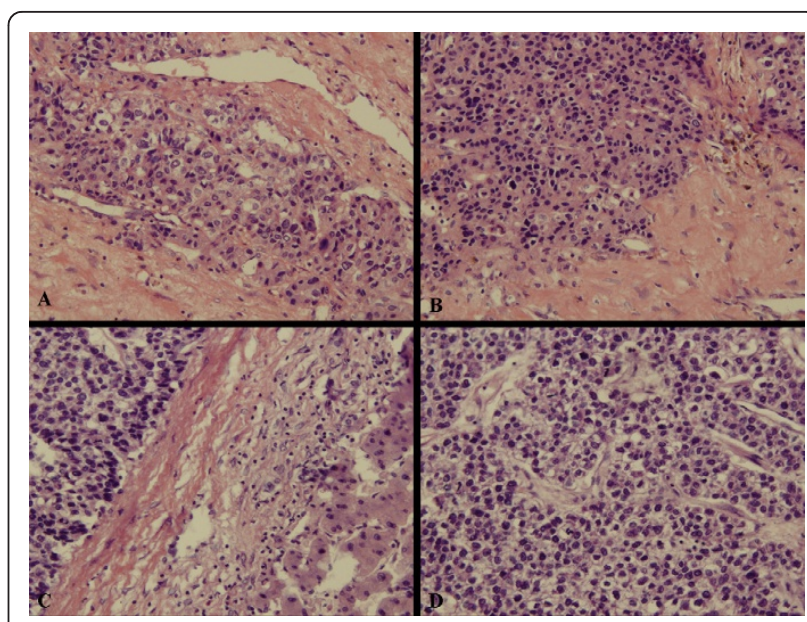

Figure 4 (A, B) A microscopic view of the tumor in the seminal vesicle: the tumor cells arranged in trabecular and solid, which is compatible with the original $\operatorname{HCC}(C, D)$.

organs such as the bladder, prostate, or rectum. Primary seminal vesicle tumors are rare and may be benign (papillary adenoma, cystadenoma, hydatid cyst, and amyloid deposition) or malignant (adenocarcinoma, sarcoma, cystosarcoma phyllodes, primary seminoma, and carcinoid). Adenocarcinoma is the most frequent malignant tumor. Therefore, we first excluded it before diagnosing the mass as metastasis from HCC. In 1956, Dalgaard and Giertson [9] established the following criteria for the diagnosis of primary seminal vesicle adenocarcinoma: 1) the tumor should be a microscopically verified carcinoma, localized exclusively or mainly to the seminal vesicle; 2) the presence of other simultaneous primary carcinoma should be excluded; and 3) the tumor should preferably resemble the architecture of the non-neoplastic seminal vesicle.

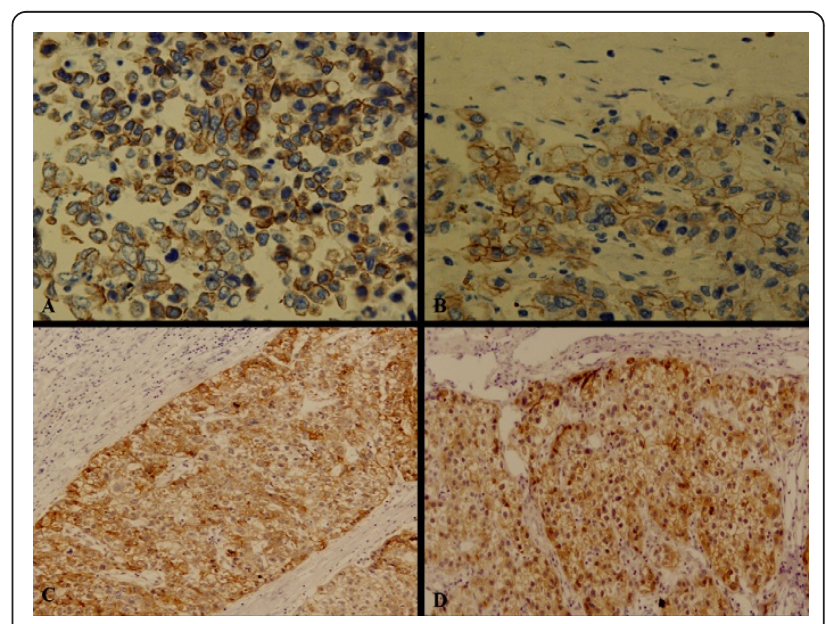

Figure 5 The tumor cells from the seminal vesicle $(A, B)$ and liver (C, D) were positive for GPC3. 


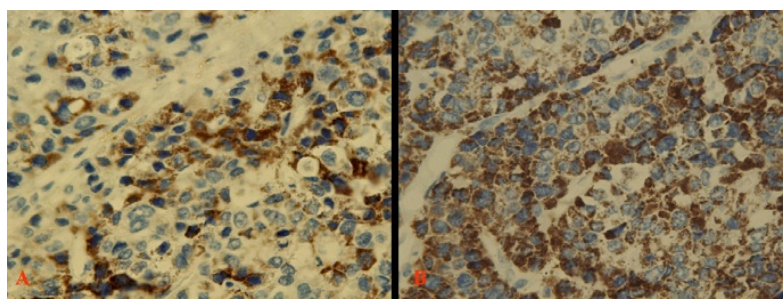

Figure 6 The tumor cells from the seminal vesicle (A) and liver (B) were positive for AFP

In the present case, the patient had a history of HCC. Moreover, according to the surgical doctor's introduction, the mass was only found in seminal vesicle during the operation. In addition, the histopathological characteristics of the mass from seminal vesicle were similar to that of primary HCC, although it had a poorly differentiated appearance. Immunohistochemically, the tumor cells were positive for GPC3, AFP, hepatocyte antigen, HepPar1, and CK18, but negative for CK7, CK20, PLAP, PSA, CA125, EMA, CD117, and CEA. Primary seminal vesicle adenocarcinoma expresses these markers as well as CK7, CA125 and CEA but not AFP, GPC3 and hepatocyte antigen [10]. It is known to all, AFP is a relatively specific but rather insensitive marker for hepatocellular differentiation and is present in only one quarter of the cases. Recently, GPC3 has been reported as novel serum and histochemical marker for HCC, with positive staining in $72 \%$ to $100 \%$ of cases [11-16]. Thus, based on the tumor cells positive reactivity for GPC3, AFP, hepatocyte antigen, Hep Par 1, and CK18, we thought that the seminal vesicle mass should firstly be considered as a metastatic HCC lesion. Of course, AFP, HepPar1 and GPC3 were not only positive in HCC. Many malignant

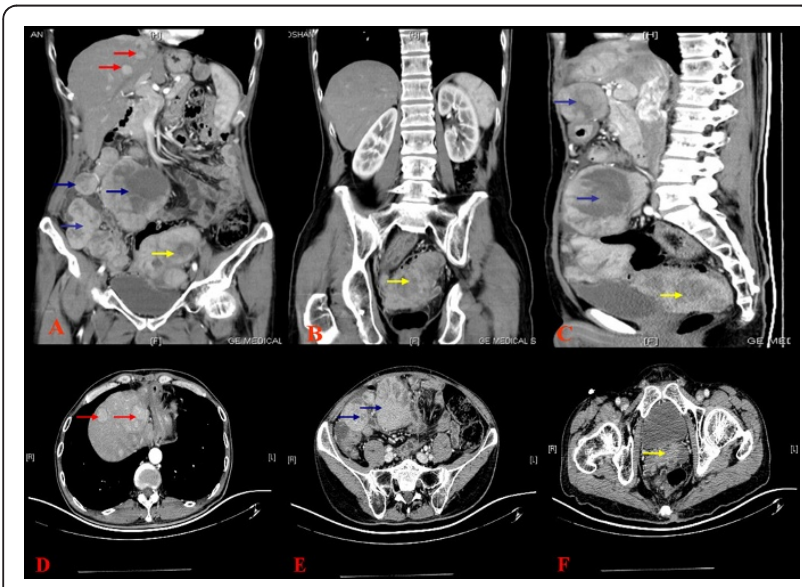

Figure 7 Computed tomography (CT) revealed multiple intrahepatic recurrent or metastatic foci and metastatic foci in abdominal and pelvic cavity. Red arrow, intrahepatic recurrent or metastatic foci; blue arrow, metastatic foci in abdominal; yellow arrow; metastatic foci in the seminal vesicle region. tumors with AFP producing and hepatoid features resembling $\mathrm{HCC}$, such as hepatoid adenocarcinoma of the stomach and primary hepatoid yolk sac tumor $(\mathrm{H}-$ YST) of ovary and testis, especially the latter, express AFP, Hep Par 1 and GPC3 [17,18]. Namely, AFP, Hep Par 1 and GPC3 are useful markers for HCC, but not entirely specific. However, the YST usually occurs in younger patients, and most of them occur in the ovaries and testis. About $20 \%$ arise in extraovarian sites, including the mediastinum, sacrococcygeal region, cervix, vulva, pelvis, and retroperitoneum [19-24]. We do not believe primary H-YST of the seminal vesicle has been reported in the literature. Moreover, gonadal dysgenesis and the presence of a residual component of typical yolk sac tumor or a polyvesicular vitelline pattern, or glandular-like structure some with mucin production, is helpful for differential diagnosis. In addition, immunohistochemically, the tumor cells of H-YSTs are positive for CK besides AFP and HepPar1, and negative for hepatocyte antigen, CK20, CEA and EMA. Thus, we finally considered it was a metastatic $\mathrm{HCC}$ lesion based on its clinical and pathological features.

No sufficient data is currently available regarding treatment for HCC with metastasis to the seminal vesicle. However, the prognosis appears to be poor. In our case, the patient had undergone regular radiofrequency ablation since the diagnosis of HCC, but intrahepatic and seminal vesicle metastatic lesions were found after half a year and 27 months, respectively. It was worse that CT revealed multiple metastatic foci in the abdominal and pelvic cavities after 32 months and 3 years, respectively.

In conclusion, the seminal vesicle is an extremely rare metastatic site for $\mathrm{HCC}$, and the prognosis is very poor. Although AFP, Hep Par 1, hepatocyte antigen and GPC3 are useful markers for HCC. They are not, however, entirely specific, showing different extent staining in hepatoid adenocarcinoma and H-YST. Thus, a combination of clinical and pathological features is necessary for a correct diagnosis, and primary tumor should be excluded before diagnosing metastatic foci,

\section{Abbreviations \\ AFP: alpha fetoprotein; CA125: cancer antigen; CEA: carcinoembryonic antigen; CT: computed tomography; CK: cytokeratin; EMA: epithelial membrane antigen; GPC3: glypican 3; HBV: hepatitis B virus; HCC: hepatocellular carcinoma; HCV: hepatitis C virus; Hep Par 1: hepatocyte paraffin-1; PLAP: placental alkaline phosphatase, PSA: prostate-specific antigen;}

\section{Acknowledgements}

This work was supported by The National Natural Science Foundation of China (No. 30800417, No. 30672013 and No. 30970789) and The National Basic Research Program (973 Program) of China (No. 2009CB521704).

\section{Author details}

'The Helmholtz Sino-German Laboratory for Cancer Research, Department of Pathology, Tangdu Hospital, the Fourth Military Medical University, 710038 Xi'an, Shaanxi Province, PR China. ${ }^{2}$ Department of Radiology, Xijing Hospital, 
the Fourth Military Medical University, 710032 Xi'an, Shaanxi Province, PR China. ${ }^{3}$ Department of General Surgery, the Second Affiliated Hospital, Xi'an Jiaotong University, 710031 Xi'an, Shaanxi Province, PR China. ${ }^{4}$ Department of Radiology, the Second Affiliated Hospital, Xi'an Jiaotong University, 710031 Xi'an, Shaanxi Province, PR China. ${ }^{5}$ Depatment of Ophthalmology, Tangdu Hospital, the Fourth Military Medical University, 710038 Xi'an, Shaanxi Province, PR China.

\section{Authors' contributions}

GL carried out the whole study and drafted the manuscript. ZMW, LYH, ZWD and HY participated in drafting the manuscript. BWJ provided the patient's history and performed the immunohistochemistry. ZMW and SLF collected the $\mathrm{CT}$ picture. ZW participated in its design and coordination and helped to draft the manuscript. All authors read and approved the final manuscript.

\section{Competing interests}

The authors declare that they have no competing interests.

Received: 18 February 2010 Accepted: 28 March 2011

Published: 28 March 2011

\section{References}

1. Ahn SH, Han KH, Park JY, Youn YH, Moon CM, Lee KS, Chon CY, Moon YM, Lee DY, Lee JT: Treatment outcome of transcatheter arterial chemoinfusion according to anticancer agents and prognostic factors in patients with advanced hepatocellular carcinoma (TNM Stage IVa). Yonsei Med J 2004, 45:847-858.

2. El-Serag HB, Davila JA, Petersen NJ, McGlynn KA: The continuing increase in the incidence of hepatocellular carcinoma in the United States: an update. Ann Intern Med 2003, 139:817-823.

3. Lau H, Fan ST, Ng IO, Wong J: Long term prognosis after hepatectomy for hepatocellular carcinoma: a survival analysis of 204 consecutive patients. Cancer 1998, 83:2302-2311.

4. Katyal S, Oliver JH III, Peterson MS, Ferris JV, Carr BS, Baron RL: Extrahepatic metastases of hepatocellular carcinoma. Radiology 2000, 216:698-703.

5. Shuto T, Hirohashi K, Kubo S, Tanaka H, Yamamoto T, Higaki I, Takemura S, Kinoshita $\mathrm{H}$ : Treatment of adrenal metastases after hepatic resection of a hepatocellular carcinoma. Dig Surg 2001, 18:294-297.

6. Si MS, Amersi F, Golish SR, Ortiz JA, Zaky J, Finklestein D, Busuttil RW, Imagawa DK: Prevalence of metastases in hepatocellular carcinoma: risk factors and impact on survival. Am Surg 2003, 69:879-885.

7. Natsuizaka M, Omura T, Akaike T, Kuwata Y, Yamazaki K, Sato T, Karino Y, Toyota J, Suga T, Asaka M: Clinical features of hepatocellular carcinoma with extrahepatic metastases. J Gastroenterol Hepatol 2005, 20:1781-1787.

8. Uka K, Aikata H, Takaki S, Shirakawa H, Jeong SC, Yamashina K, Hiramatsu A, Kodama H, Takahashi S, Chayama K: Clinical features and prognosis of patients with extrahepatic metastases from hepatocellular carcinoma. World J Gastroentrol 2007, 21:414-420.

9. Dalgaard JB, Giertson JC: Primary carcinoma of the seminal vesicle: Case and survey. Acta Pathol Microbiol Scand 1956, 39:255-267.

10. Tarján M, Ottlecz I, Tot T: primary adenocarcinoma of the seminal vesicle. Indian J Urol 2009, 25:143-145.

11. Capurro M, Wanless IR, Sherman M, Deboer G, Shi W, Miyoshi E, Filmus J: Glypican-3: a novel serum and histochemical marker for hepatocellular carcinoma. Gastroenterology 2003, 125:89-97.

12. Yamauchi N, Watanabe A, Hishinuma M, Ohashi K, Midorikawa $Y$, Morishita Y, Niki T, Shibahara J, Mori M, Makuuchi M, Hippo Y, Kodama T, Iwanari H, Aburatani $\mathrm{H}$, Fukayama M: The glypican 3 oncofetal protein is a promising diagnostic marker for hepatocellular carcinoma. Mod Pathol 2005, 18:1591-1598.

13. Libbrecht L, Severi T, Cassiman D, Vander Borght S, Pirenne J, Nevens F, Verslype C, van Pelt J, Roskams T: Glypican-3 expression distinguishes small hepatocellular carcinomas from cirrhosis, dysplastic nodules, and focal nodular hyperplasia-like nodules. Am J Surg Pathol 2006, 30:1405-1411.

14. Wang XY, Degos F, Dubois S, Tessiore S, Allegretta M, Guttmann RD, Jothy S, Belghiti J, Bedossa P, Paradis V: Glypican-3 expression in hepatocellular tumors: diagnostic value for preneoplastic lesions and hepatocellular carcinomas. Hum Pathol 2006, 37:1435-1441.
15. Llovet JM, Chen Y, Wurmbach E, Roayaie S, Fiel MI, Schwartz M, Thung SN, Khitrov G, Zhang W, Villanueva A, Battiston C, Mazzaferro V, Bruix J, Waxman S, Friedman SL: A molecular signature to discriminate dysplastic nodules from early hepatocellular carcinoma in HCV cirrhosis. Gastroenterology 2006, 131:1758-1767.

16. Di Tommaso L, Franchi G, Park YN, Fiamengo B, Destro A, Morenghi E, Montorsi M, Torzilli G, Tommasini M, Terracciano L, Tornillo L, Vecchione R, Roncalli M: Diagnostic value of HSP70, glypican 3, and glutamine synthetase in hepatocellular nodules in cirrhosis. Hepatology 2007, 45:725-734.

17. Esheba GE, Pate LL, Longacre TA: Oncofetal protein glypican-3 distinguishes yolk sac tumor from clear cell carcinoma of the ovary. Am J Surg Pathol 2008, 32:600-607.

18. Fan Z, van de Rijn M, Montgomery K, Rouse RV: Hep par 1 antibody stain for the differential diagnosis of hepatocellular carcinoma: 676 tumors tested using tissue microarrays and conventional tissue sections. Mod Pathol 2003, 16:137-144.

19. Deb AR, Sarkar S, Chakraborty S, Aich RK, Das D, Mitra D, Gangopadhyay S, De A: Primary mediastinal yolk sac tumour in a young female. I Indian Med Assoc 2008, 106:604.

20. Mufti T, Khan MS, Muzher-U-Dua, Waqar F: Malignant sacrococcygeal yolk sac (endodermal sinus) tumor. J Ayub Med Coll Abbottabad 2002, 14:28-30.

21. Traen K, Logghe H, Maertens J, Mattelaere C, Moerman P, Vergote I: Endodermal sinus tumor of the vulva: successfully treated with highdose chemotherapy. Int I Gynecol Cancer 2004, 14:998-1003.

22. Yadav K, Singh G, Budhiraja S, Radhika S: Endodermal sinus tumour of cervix-case report. Indian J Cancer 1996, 33:43-45.

23. Tseng MJ, Jung SM: Primary extra-gonadal yolk-sac tumour of pelvis with unusual presentation. Lancet Oncol 2007, 8:179-180.

24. De Backer A, Madern GC, Pieters R, Haentjens P, Hakvoort-Cammel FG Oosterhuis JW, Hazebroek FW: Influence of tumor site and histology on long-term survival in 193 children with extracranial germ cell tumors. Eur J Pediatr Surg 2008, 18:1-6.

\section{Pre-publication history}

The pre-publication history for this paper can be accessed here: http://www.biomedcentral.com/1471-2407/11/111/prepub

\section{doi:10.1186/1471-2407-11-111}

Cite this article as: Gong et al: Seminal vesicle metastasis after partial hepatectomy for hepatocellular carcinoma. BMC Cancer 2011 11:111.

\section{Submit your next manuscript to BioMed Central and take full advantage of:}

- Convenient online submission

- Thorough peer review

- No space constraints or color figure charges

- Immediate publication on acceptance

- Inclusion in PubMed, CAS, Scopus and Google Scholar

- Research which is freely available for redistribution

Submit your manuscript a www.biomedcentral.com/submit
Ciomed Central 